\title{
Modern brain mapping - what do we map nowadays?
}

\author{
Maria Nazarova ${ }^{1,2 *}$ and Evgeny Blagovechtchenski ${ }^{1,3}$ \\ ${ }^{1}$ Centre for Cognition and Decision Making, National Research University Higher School of Economics, Moscow, Russia, \\ ${ }^{2}$ Research Center of Neurology, Moscow, Russia, ${ }^{3}$ Institute of Translational Biomedicine, St. Petersburg State University, St. \\ Petersburg, Russia
}

Keywords: brain mapping, motor control, sensory systems, history of brain mapping, function localization

\section{Introduction}

The problem of function localization in the brain is one of the most fundamental in neuroscience. There are two opposite paradigms relating to the problem: "modularism," also known as "localism," versus "holism," which have been discussed for a long time $(1,2)$. The debate in favor of one or another view can still be traced at all methodological levels - from the cell to the system. In this opinion paper we want to raise a question - what is meant nowadays by brain mapping? In addition, we want to highlight the necessity of being aware of occasionally occurring discontinuity in the research at different methodological scales. This problem is evident for experts in the field, but not always sufficiently so for early career researches. We will try to describe the difficulties of modern brain mapping primarily by looking at one of the currently best-studied functions - motor function.

\section{OPEN ACCESS \\ Edited by: \\ History of Opposition of Modular Versus Holistic Conceptions of Brain Organization}

Domenica Veniero,

University of Glasgow, UK

Reviewed by:

Mikhail Lebedev,

Duke University, USA

*Correspondence:

Maria Nazarova

mnazarova@hse.ru

Specialty section:

This article was submitted to

Neuropsychiatric Imaging and

Stimulation, a section of the journal

Frontiers in Psychiatry

Received: 30 January 2015

Accepted: 27 May 2015

Published: 16 June 2015

Citation:

Nazarova M and Blagovechtchenski E (2015) Modern brain mapping - what

do we map nowadays?

Front. Psychiatry 6:89.

doi: 10.3389/fpsyt.2015.00089

A somewhat artificial opposition of "modular" and "holistic" organization of the brain has been evident in neuroscience from 18th century, and started mostly as a disagreement between physiologists working on animals and clinicians studying brain lesions in humans (1-3). A first revision of the term "function" by a clinician and a step away from hardwired localism was performed by the neurologists J. H. Jackson at the end of 19th century who wrote that "localization of a symptom is not localization of a function" (4). In the beginning of the 20th century, a paradigm shift occurred toward gestalt psychology, which changed the trend of research at the macro-scale level towards a more holistic view (2). A prime example of a confrontation at the micro-scale at the same time was the debate of Golgi and Cajal regarding the essence of a neuron (5). In 1937, a neurosurgeon W. Penfield performed the first cortical cartography in humans and published an iconic description of sensory and motor homunculi (6). In the second quarter of the 20th century, the concept of a function as a goal-dependent entity appeared in the form of theory of movements (7) and theory of functional systems (8), both viewing a function as a non-rigid goal-dependent entity. To date, it is usually postulated that localism and holism have been replaced by "connectionism," with many studies nowadays trying to find interactions between brain regions and not the function of these regions by themselves $(9,10)$. However, it seems there is still a tendency to favor localism, especially in the cognitive sciences $(11,12)$. Perhaps, this is due to the fact that modern non-invasive methods, such as PET, fMRI or TMS, are mostly associated with functional mapping of the brain based on M. Minsky's philosophy that "minds are what brains do." 


\section{Discontinuity of the Motor Research of Different Methodological Scales}

The question remains open of how cortical "activation" at the macro-level, viewed for example with fMRI or EEG, is linked to micro-scale phenomena such as single neuron activity in the spinal cord in awake animals (especially in humans) $(13,14)$. There is a large community of researches studying ways of activation of a particular alpha-motor neurons in the spinal cord (15-17); scientists working on the level of a single neuron usually associate it to a specific task $(16,18)$. Thereby, those who work with slices of the spinal cord are well aware of how to activate a certain motoneuron (19), but it is still difficult to bridge these phenomena with activation of the cortex (15). Modern macroscale approaches connecting peripheral and central recording, such as TMS-EEG and corticomuscular coherence, including biofeedback, are trying to overcome this gap (20).

A good example of a discontinuity in motor research at different methodological scales is the phenomena of convergence and divergence of motor cortex organization. They are well known in micro- and meso-scale studies. For example, in the invasive brain-computer interface (BCI) research, principles like neural degeneracy and neuronal multitasking were formulated (21). However, these phenomena are still widely overlooked in the research at the macro-scale level (22). For instance, a commonly used term in macro-scale research is an "area of a muscle cortical representation" $(23,24)$, which is suitable for practical use like presurgical motor mapping (25), but is physiologically dubious considering the proven fact that some pyramidal cells may broadly innervate corresponding alpha motoneurons relating to activation of different muscles, even of different limb segments (26-28).

\section{Goal-Driven Concept of a Function - Problem of Awake Versus Anesthetized Animals}

Clearly demonstrated in many studies, context and goaldependency of a motor function $(29,30)$ brings us back to the necessity to revise the concept of a function as an environment and goal-dependent entity. Since a large amount of classical mapping experiments were performed on anesthetized animals, where conditions are stable and there is no context or goal directed behavior, one should be careful when interpreting the results of these experiments. The data obtained in anesthetized animals are widely used as a teaching material: the construction of the motor and sensory homunculus is an essential part of most neuroscience textbooks $(31,32)$. However, the experiments on awake animals raise doubts about this rigid structure (33).

\section{Renaissance of a Goal-Driven Concept of a Function in Neurorehabilitation}

The problem of function localization in the brain is relevant for the development of new approaches to rehabilitation after brain damage. Hence, in the 80 s and 90 s, the popularity of the idea of long-term brain reorganization resulted in the birth of neurorehabilitation as a new and fruitful field $(34,35)$. Nowadays, the growing understanding of the on-line instability and goal-dependency of a function is bringing new trends to this field. Thus, new approaches in neurorehabilitation are oriented not toward simple movement training but toward the recovery of a whole goal-oriented action $(36,37)$. The renaissance of a systematic view on function resulted in the appearance of new techniques, comprised of simultaneous application of many modalities, including visual biofeedback such as mirror therapy $(38,39)$ or multimodal biofeedback during motor rehabilitation (40).

Understanding function in a corresponding context necessitates the development of closed-loop approaches of therapeutic brain stimulation (like TMS), instead of stimulation of different cortical regions at rest. These closed-loop approaches require the elaboration of protocols for central-peripheral stimulation coupling for the optimal modulation of the recovering brain $(41,42)$. Such task-dependent closed-loop approaches can be combined with brain-state guided stimulation. The last few years have witnessed an increase in studies identifying brain-states favorable for stimulation, for example based on pre-stimulus EEG $(43,44)$. This is going to lead to the development of new protocols for therapeutic stimulation with better timing. A similar methodology is already successfully used in the field of invasive BCI combining brain activity recording with cortical stimulation (45, 46). Favorable preconditioning brain-states could also be deliberately achieved using approaches such as transcranial alternating current stimulation (tACS), allowing brain stimulation with a specific frequency during a task (47). The dynamic nature of a function makes evident the impossibility of a one-size-fits-allstrategy (48), and highlights the need for dynamic revision of the targets and strategies throughout the recovery process in brain damage patients.

\section{Conclusion}

Despite the fact that the field is moving from the holism-localism opposition toward a paradigm of connectionism, which can be seen in the development of such big projects as Connectome or Human Brain Project (49), we still lack a clear understanding of how to address the problem of functions localization. We wanted to highlight the importance of being careful with extrapolations based on the a priori assumptions, which appear sometimes to be different at different methodological scales. A promising new approach which may lead to a new understanding of how to distinguish networks and areas in the brain may be optogenetics, a method allowing the stimulation not of the specific regions of the brain, but of the specific networks and inputs (50). Another encouraging trend is the growing $\mathrm{BCI}$ field which combines observational and interventional approaches (21).

\section{Acknowledgments}

The authors are grateful to Dr. Vadim Nikulin for discussions. The work was supported by RSCF grant no: 14-18-02522. 


\section{References}

1. Flourens P. Expériences Sur Le Système Nerveux Par P. Flourens, Faisant Suite Aux 'Recherches Expérimentales Sur Les Propriétés et Les Fonctions Du Système Nerveux Dans Les Animaux Vertébrés' Du Même Auteur. Paris: Crevot (1825).

2. Luria AR. Higher cortical functions in man. (Originally published by Moscow University Press, 1962.) Translated by Basil Haigh. New York: basic books, 1966. Behav Sci (1967) 12:234-6. doi:10.1002/bs.3830120308

3. Greenblatt SH. Phrenology in the science and culture of the 19th century. Neurosurgery (1995) 37(4):790-804.

4. Jacyna LS. Process and progress: John Hughlings Jackson's philosophy of science. Brain? (2011) 134(Pt 10):3121-6. doi:10.1093/brain/awr236

5. Glickstein M. Golgi and Cajal: the neuron doctrine and the 100th anniversary of the 1906 nobel prize. Curr Biol (2006) 16(5):R147-51. doi:10.1016/j.cub.2006. 02.053

6. Penfield W, Boldrey E. Somatic motor and sensory representation in the cerebral cortex of man as studied by electrical stimulation. Brain (1937) 60(4):389-443. doi:10.1093/brain/60.4.389

7. Bernshtein N. The coordination and Regulation of Movements. Oxford, NY: Pergamon Press (1967).

8. Anokhin PK. The Problem of Center and Periphery in the Contemporary Physiology of Nervous Activity. Moscow: Gosizdat, Gorky (1935). p. 9-70.

9. Arai N, Lu MK, Ugawa Y, Ziemann U. Effective connectivity between human supplementary motor area and primary motor cortex: a paired-coil TMS study. Exp Brain Res (2012) 220(1):79-87. doi:10.1007/s00221-012-3117-5

10. Bortoletto M, Veniero D, Thut G, Miniussi C. The contribution of TMS-EEG coregistration in the exploration of the human cortical connectome. Neurosci Biobehav Rev (2014) 49C:114-24. doi:10.1016/j.neubiorev.2014.12.014

11. Arsalidou M, Taylor MJ. Is $2+2=4$ ? Meta-analyses of brain areas needed for numbers and calculations. Neuroimage (2011) 54(3):2382-93. doi:10.1016/j. neuroimage.2010.10.009

12. Kovach CK, Daw ND, Rudrauf D, Tranel D, O’Doherty JP, Adolphs R. Anterior prefrontal cortex contributes to action selection through tracking of recent reward trends. J Neurosci (2012) 32(25):8434-42. doi:10.1523/JNEUROSCI. 5468-11.2012

13. Harel N, Bolan PJ, Turner R, Ugurbil K, Yacoub E. Recent advances in highresolution MR application and its implications for neurovascular coupling research. Front Neuroenergetics (2010) 2:130. doi:10.3389/fnene.2010.00130

14. Isa T, Kinoshita M, Nishimura $Y$. Role of direct vs. Indirect pathways from the motor cortex to spinal motoneurons in the control of hand dexterity. Front Neurol (2013) 4:191. doi:10.3389/fneur.2013.00191

15. Stuart DG. Integration of posture and movement: contributions of Sherrington, Hess, and Bernstein. Hum Mov Sci (2005) 24(5-6):621-43. doi:10.1016/j. humov.2005.09.011

16. Wilson JM, Blagovechtchenski E, Brownstone RM. Genetically defined inhibitory neurons in the mouse spinal cord dorsal horn: a possible source of rhythmic inhibition of motoneurons during fictive locomotion. J Neurosci (2010) 30(3):1137-48. doi:10.1523/JNEUROSCI.1401-09.2010

17. Bretzner F, Gilbert F, Baylis F, Brownstone RM. Target populations for first-inhuman embryonic stem cell research in spinal cord injury. Cell Stem Cell (2011) 8(5):468-75. doi:10.1016/j.stem.2011.04.012

18. Pettersson LG, Alstermark B, Blagovechtchenski E, Isa T, Sasaski S. Skilled digit movements in feline and primate - recovery after selective spinal cord lesions. Acta Physiol (Oxf) (2007) 189:141-54. doi:10.1111/j.1748-1716.2006.01650.x

19. Lundberg A. The supraspinal control of transmission in spinal reflex pathways. Electroencephalogr Clin Neurophysiol (1967) 25:35-46.

20. Von Carlowitz-Ghori K, Bayraktaroglu Z, Waterstraat G, Curio G, Nikulin VV. Voluntary control of corticomuscular coherence through neurofeedback: a proof-of-principle study in healthy subjects. Neuroscience (2015) 290:243-54. doi:10.1016/j.neuroscience.2015.01.013

21. Nicolelis MA, Lebedev MA. Principles of neural ensemble physiology underlying the operation of brain-machine interfaces. Nat Rev Neurosci (2009) 10(7):530-40. doi:10.1038/nrn2653

22. Schieber MH. Constraints on somatotopic organization in the primary motor cortex. J Neurophysiol (2001) 86(5):2125-43.

23. Corneal SF, Butler AJ, Wolf SL. Intra- and intersubject reliability of abductor pollicis brevis muscle motor map characteristics with transcranial magnetic stimulation. Arch Phys Med Rehabil (2005) 86(8):1670-5. doi:10.1016/j.apmr. 2004.12.039
24. Espadaler J, Rogić M, Deletis V, Leon A, Quijada C, Conesa G. Representation of cricothyroid muscles at the primary motor cortex (M1) in healthy subjects, mapped by navigated transcranial magnetic stimulation (nTMS). Clin Neurophysiol (2012) 123(11):2205-11. doi:10.1016/j.clinph.2012.04.008

25. Takahashi S, Vajkoczy P, Picht T. Navigated transcranial magnetic stimulation for mapping the motor cortex in patients with rolandic brain tumors. Neurosurg Focus (2013) 34(4):E3. doi:10.3171/2013.1.FOCUS133

26. McKiernan BJ, Marcario JK, Karrer JH, Cheney PD. Corticomotoneuronal postspike effects in shoulder, elbow, wrist, digit, and intrinsic hand muscles during a reach and prehension task. J Neurophysiol (1998) 80(4):1961-80.

27. McKiernan BJ, Marcario JK, Karrer JH, Cheney PD. Correlations between corticomotoneuronal $(\mathrm{CM})$ cell postspike effects and cell-target muscle covariation. J Neurophysiol (2000) 83(1):99-115.

28. Rathelot JA, Strick PL. Muscle representation in the macaque motor cortex: an anatomical perspective. Proc Natl Acad Sci U S A (2006) 103(21):8257-62. doi:10.1073/pnas.0602933103

29. Möttönen R, Watkins KE. Using TMS to study the role of the articulatory motor system in speech perception. Aphasiology (2012) 26(9):1103-18. doi:10.1080/ 02687038.2011.619515

30. Bangert M, Peschel T, Schlaug G, Rotte M, Drescher D, Hinrichs H, et al. Shared networks for auditory and motor processing in professional pianists: evidence from fMRI conjunction. Neuroimage (2006) 30(3):917-26. doi:10. 1016/j.neuroimage.2005.10.044

31. Kandel ER, Schwartz JH, Jessell TM, Siegelbaum SA, Hudspeth AJ. Voluntary movement: the primary motor cortex. In: Principles of Neural Science. 5th ed. (2012). p. 835-65.

32. Bear MF, Connors BW, Paradiso MA. Neuroscience: Exploring the Brain. 3rd ed. Philadelphia: Lippincott Williams \& Wilkins (2007).

33. Earland K, Lee M, Shaw P, Law J. Overlapping structures in sensory-motor mappings. PLoS One (2014) 9(1):e84240. doi:10.1371/journal.pone.0084240

34. Dombovy ML, Bach-y-Rita P. Clinical observations on recovery from stroke. Adv Neurol (1988) 47:265-76.

35. Kaas JH, Merzenich MM, Killackey HP. The reorganization of somatosensory cortex following peripheral nerve damage in adult and developing mammals. Annu Rev Neurosci (1983) 6:325-56. doi:10.1146/annurev.ne.06. 030183.001545

36. Wevers L, van de Port I, Vermue M, Mead G, Kwakkel G. Effects of task-oriented circuit class training on walking competency after stroke: a systematic review. Stroke (2009) 40(7):2450-9. doi:10.1161/STROKEAHA.108.541946

37. Schweighofer N, Choi Y, Winstein C, Gordon J. Task-oriented rehabilitation robotics. Am J Phys Med Rehabil (2012) 91(11 Suppl 3):S270-9. doi:10.1097/ PHM.0b013e31826bcd42

38. Ramachandran VS, Altschuler EL. The use of visual feedback, in particular mirror visual feedback, in restoring brain function. Brain? (2009) 132(Pt 7): 1693-710. doi:10.1093/brain/awp135

39. Butorina A, Prokofyev A, Nazarova M, Litvak V, Stroganova T. The mirror illusion induces high gamma oscillations in the absence of movement. Neuroimage (2014) 103C:181-91. doi:10.1016/j.neuroimage.2014.09.024

40. Cameirão MS, Badia SB, Oller ED, Verschure PF. Neurorehabilitation using the virtual reality based rehabilitation gaming system: methodology, design, psychometrics, usability and validation. J Neuroeng Rehabil (2010) 7:48. doi:10. 1186/1743-0003-7-48

41. Gharabaghi A, Kraus D, Leão MT, Spüler M, Walter A, Bogdan M, et al. Coupling brain-machine interfaces with cortical stimulation for brain-state dependent stimulation: enhancing motor cortex excitability for neurorehabilitation. Front Hum Neurosci (2014) 8:122. doi:10.3389/fnhum.2014.00122

42. Buetefisch C, Heger R, Schicks W, Seitz R, Netz J. Hebbian-type stimulation during robot-assisted training in patients with stroke. Neurorehabil Neural Repair (2011) 25(7):645-55. doi:10.1177/1545968311402507

43. Mäki H, Ilmoniemi RJ. EEG oscillations and magnetically evoked motor potentials reflect motor system excitability in overlapping neuronal populations. Clin Neurophysiol (2010) 121(4):492-501. doi:10.1016/j.clinph.2009.11.078

44. Ferreri F, Vecchio F, Ponzo D, Pasqualetti P, Rossini PM. Time-Varying Coupling of EEG oscillations predicts excitability fluctuations in the primary motor cortex as reflected by motor evoked potentials amplitude: an EEG-TMS study. Hum Brain Mapp (2014) 35(5):1969-80. doi:10.1002/hbm.22306

45. Fitzsimmons NA, Drake W, Hanson TL, Lebedev MA, Nicolelis MAL. Primate reaching cued by multichannel spatiotemporal cortical microstimulation. J Neurosci (2007) 27(21):5593-602. doi:10.1523/JNEUROSCI.5297-06.2007 
46. Manzur HE, Alvarez J, Babul C, Maldonado PE. Synchronization across sensory cortical areas by electrical microstimulation is sufficient for behavioral discrimination. Cereb Cortex (2013) 23(12):2976-86. doi:10.1093/cercor/bhs288

47. Feurra M, Pasqualetti P, Bianco G, Santarnecchi E, Rossi A, Rossi S. Statedependent effects of transcranial oscillatory currents on the motor system: what you think matters. J Neurosci (2013) 33(44):17483-9. doi:10.1523/JNEUROSCI. 1414-13.2013

48. Di Pino G, Pellegrino G, Assenza G, Capone F, Ferreri F, Formica D, et al. Modulation of brain plasticity in stroke: a novel model for neurorehabilitation. Nat Rev Neurol (2014) 10(10):597-608. doi:10.1038/nrneurol.2014.162

49. Kandel ER, Markram H, Matthews PM, Yuste R, Koch C. Neuroscience thinks big (and collaboratively). Nat Rev Neurosci (2013) 14(9):659-64. doi:10.1038/ nrn3578
50. Nabavi S, Fox R, Proulx CD, Lin JY, Tsien RY, Malinow R. Engineering a memory with LTD and LTP. Nature (2014) 511(7509):348-52. doi:10.1038/ nature13294

Conflict of Interest Statement: The authors declare that the research was conducted in the absence of any commercial or financial relationships that could be construed as a potential conflict of interest.

Copyright (C) 2015 Nazarova and Blagovechtchenski. This is an open-access article distributed under the terms of the Creative Commons Attribution License (CC BY). The use, distribution or reproduction in other forums is permitted, provided the original author(s) or licensor are credited and that the original publication in this journal is cited, in accordance with accepted academic practice. No use, distribution or reproduction is permitted which does not comply with these terms. 